\title{
A single dose of the topical carbonic anhydrase inhibitor MK-927 decreases IOP in patients
}

\author{
N Pfeiffer, R Hennekes, E A Lippa, F Grehn, H Garus, F L Brunner-Ferber
}

\begin{abstract}
MK-927 is a novel topical carbonic anhydrase inhibitor (CAI). We present the first singledose clinical trial of MK-927 in 24 patients with bilateral primary open-angle glaucoma or ocular hypertension. This investigation was conducted as a two-centre, double-masked, randomised, placebo controlled study. Patients received one drop of 2\% MK-927 in one eye and placebo in the other eye. Modified diurnal intraocular pressure (IOP) curves were performed before the study and on one treatment day. A single dose of $2 \%$ MK-927 induced a peak mean IOP decrease of $10.5 \mathrm{mmHg}$ at 4.5 hours postdose. With compensation for diurnal variation, as determined by the prestudy diurnal pressure curve, the net peak mean reduction of IOP caused by MK-927 was 7.5 mmHg versus a corresponding net change of $1.4 \mathrm{mmHg}$ in the contralateral placebo treated eye. Thus a single dose of MK-927 gave a clinically significant IOP reduction in patients.
\end{abstract}

At present, the medical treatment of glaucoma depends mainly on the topical application of parasympathomimetics, sympathomimetics, and $\beta$-blockers. Oral CAIs have been in use for the treament of glaucoma since $1954 .^{1}$ Despite their efficacy, lack of ocular side effects and little escape phenomenon their clinical use is limited because of systemic side effects. These include paraesthesiae, fatigue, gastrointestinal disturbances, and loss of libido, all resulting in poor patient compliance. In addition serious side effects such as renal calculi, electrolyte imbalance, and aplastic anaemia may also occur. From 1955 onwards $^{23}$ attempts have been made to use acetazolamide in a topical preparation which it was hoped would have the advantages of an oral CAI while avoiding its systemic side effects. However, intraocular penetration was insufficient to produce a substantial reduction of IOP. Various other CAIs applied topically have been disappointing clinically despite encouraging results in pharmacological models. ${ }^{4}$ Recently a new gel formulation of aminozolamide (6-amino2-benzothiazole sulphonamide) has been shown to reduce the IOP to some extent when applied topically. ${ }^{5}$ Another agent, 6-hydroxybenzo[b]thiophene-2-sulphonamide, reduced the IOP in rabbits $^{6}$ but failed to do so in man. ${ }^{7}$

The compound MK-927 (5, 6-dihydro-4(2-methylpropyl) amino-4-H-thieno-(2, 3-b) thiopyran-2-sulphonamide 7, 7-dioxide hydrochloride, see Fig 1 for structural formula) is a new, highly water soluble CAI. ${ }^{89}$ When given topically it reduces the IOP in normotensive rabbits ${ }^{10}$ in the $\alpha$-chymotrypsin rabbit model of ocular hypertension" and in laser induced ocular hypertensive cynomolgus monkeys. ${ }^{12}$ Topical $2 \%$ MK-927 was shown to be acceptably tolerable and to reduce the IOP in healthy, normal volunteers. ${ }^{13}$

We now report the first single-drop study of MK-927 in patients with primary open-angle glaucoma or ocular hypertension.

\section{Patients and methods}

The study was reviewed and approved by the Ethical Review Committee of Freiburg University. Informed consent was obtained from each patient before entering the study.

Patients were selected from two German University Eye Hospitals based on a medical history and an ophthalmological examination consistent with the diagnosis of primary open-angle glaucoma or ocular hypertension. Patients were to be male or postmenopausal or sterilised females. Exclusion criteria were: history of angle closure or secondary glaucoma, history of intraocular surgery or ocular trauma; ocular inflammation; concomitant medication affecting IOP; visual acuity worse than 20/100; wearing of contact lenses; or significant risk from discontinuation of the current glaucoma medication.

If patients were considered eligible all previous hypotensive therapy was discontinued for a minimum of 72 hours for parasympathomimetics and 14 days for all other ocular hypotensive medications. After that washout period the patients returned to the clinic, and a prestudy diurnal IOP curve was performed with IOPs measured bilaterally at $1000,1100,1200,1300$, 1430,1600 , and 1800 hours. To be admitted into the study, the IOP at 1000 had to be $\geqslant 24 \mathrm{mmHg}$ in each eye, with a difference between eyes of $\leqslant 6$ $\mathrm{mmHg}$.
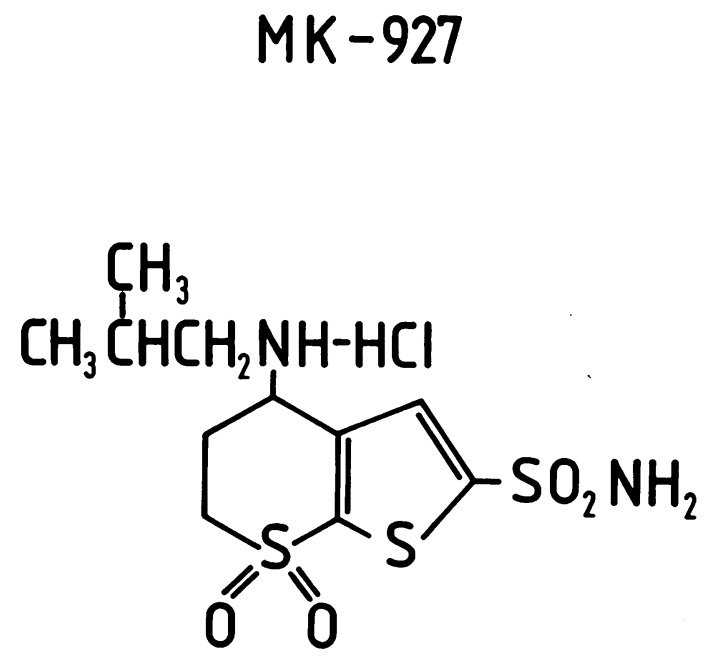

Figure 1: Structural formula of $M K-927: 5,6$-dihydro-4(methylpropyl)amino-4-H-thieno [2,3-b]thiopyran-2-

sulphonamide 7,7-dioxide hydrochloride.
Correspondence to: Dr Norbert Pfeiffer Universitäts-Augenklinik Germany.

Accepted for publication 2 February 1990 


\begin{tabular}{|c|c|c|c|c|c|c|c|c|c|c|c|}
\hline & \multirow[b]{3}{*}{$\begin{array}{l}\text { Prestudy day, } \\
\text { day }-14 \text { to }-2\end{array}$} & \multicolumn{10}{|c|}{ Treatment day } \\
\hline & & \multicolumn{10}{|c|}{ Time after administration of drug } \\
\hline & & $0^{\star}$ & ot & $10 \mathrm{~min}$ & $30 \mathrm{~min}$ & $1 \mathrm{~h}$ & $2 h$ & $3 h$ & $4 \cdot 5 h$ & $6 h$ & $8 h$ \\
\hline $\begin{array}{l}\text { Pretreatment diurnal IOP } \\
\text { curve (day }-7 \text { to }-2 \text { ) } \\
\text { Symptomatology } \\
\text { Visual acuity } \\
\text { Anterior segment examination } \\
\text { Intraocular pressure } \\
\text { Instillation of MK-927/placebo } \\
\text { Ophthalmoscopy } \\
\text { Gonioscopy (within } 6 \text { months) } \\
\text { Visual field (within } 3 \text { weeks) }\end{array}$ & $\begin{array}{l}\mathrm{X} \ddagger \\
\mathbf{X} \\
\mathbf{X} \\
\mathbf{X} \\
\mathbf{X} \dagger \\
\mathbf{X} \\
\mathbf{X} \\
\mathbf{X}\end{array}$ & $\begin{array}{l}\mathbf{X} \\
\mathbf{X} \\
\mathbf{X} \\
\mathbf{X}\end{array}$ & $\mathrm{X}$ & $\begin{array}{l}\mathrm{X} \\
\mathrm{X} \\
\mathrm{X}\end{array}$ & $\begin{array}{l}\mathrm{X} \\
\mathrm{X} \\
\mathrm{X}\end{array}$ & $\begin{array}{l}X \\
X \\
X \\
X\end{array}$ & $\begin{array}{l}X \\
X \\
X \\
X\end{array}$ & $\begin{array}{l}\mathbf{X} \\
\mathbf{X} \\
\mathbf{X} \\
\mathbf{X}\end{array}$ & $\begin{array}{l}X \\
X \\
X \\
X\end{array}$ & $\begin{array}{l}\mathbf{X} \\
\mathbf{X} \\
\mathbf{X} \\
\mathbf{X}\end{array}$ & $\begin{array}{l}\mathbf{X} \\
\mathbf{X} \\
\mathbf{X} \\
\mathbf{X} \\
\mathbf{X} \rrbracket\end{array}$ \\
\hline
\end{tabular}

The patients returned two to seven days after the prestudy diurnal curve had been done. Visual acuity was tested, and bilateral IOPs were measured at 1000 . Immediately afterwards one eye received one drop of $2 \%$ MK- 927 ophthalmic solution and the other eye received one drop of placebo (vehicle). This was followed by a diurnal IOP curve like that before the study, namely, at $1,2,3,4 \cdot 5,5,6$, and 8 hours after treatment. At 10 and 30 minutes after treatment and before all measurements of IOP, the visual acuity was tested, an examination of the anterior segment was performed, and the patients were asked about symptoms (Table I).

This investigation was conducted as a twocentre, double-masked, randomised, placebocontrolled study. The administration of MK-927 or placebo to the right or left eye was randomised.

\section{STATISTICAL METHODS}

Differences between prestudy day and treatment day diurnal curves were compared at each time point by a paired $t$ test (2-tailed, type I error set at 0.05 ). The primary response variable way was change in IOP from predose on the treatment day minus the corresponding IOP change on the prestudy diurnal curve. A between-eye analysis was done by analysis of variance.

\section{Results}

Twenty-seven patients entered the study, but two had to be excluded for inadvertent concomitant ocular hypotensive treatment and one for previous exposure to atropine. Hence 24 patients completed the study in accordance with

TABLE II Effect of a single drop of $2 \% M K-927$ versus placebo

\begin{tabular}{|c|c|c|c|c|c|c|}
\hline \multicolumn{4}{|c|}{$M K-927$ treated eye } & \multicolumn{3}{|c|}{ Placebo-treated eye } \\
\hline Time & $\begin{array}{l}\text { Prestudy } \\
\text { day }\end{array}$ & $\begin{array}{l}\text { Treatment } \\
\text { day }\end{array}$ & $p^{\star}$ & $\begin{array}{l}\text { Prestudy } \\
\text { day }\end{array}$ & $\begin{array}{l}\text { Treatment } \\
\text { day }\end{array}$ & $p^{\star}$ \\
\hline $\begin{array}{l}1000 \\
1100 \\
.1200 \\
1300 \\
1430 \\
1600 \\
1800\end{array}$ & $\begin{array}{l}30 \cdot 5(1 \cdot 2) \\
30 \cdot 3(1 \cdot 4) \\
29 \cdot 1(1 \cdot 3) \\
27 \cdot 8(1 \cdot 1) \\
27 \cdot 5(1 \cdot 2) \\
26 \cdot 5(1 \cdot 3) \\
26 \cdot 9(1 \cdot 3)\end{array}$ & $\begin{array}{l}30 \cdot 9(1 \cdot 5) \\
26 \cdot 3(1 \cdot 4) \\
22.9(1 \cdot 3) \\
21 \cdot 1(1 \cdot 1) \\
20 \cdot 4(0 \cdot 9) \\
21.3(0 \cdot 9) \\
23.6(1 \cdot 3)\end{array}$ & $\begin{array}{l}\text { ns } \\
0 \cdot 05 \\
0.001 \\
0.001 \\
0.001 \\
0.01 \\
0.05\end{array}$ & $\begin{array}{l}30 \cdot 6(1 \cdot 3) \\
30 \cdot 2(1 \cdot 5) \\
28 \cdot 7(1 \cdot 4) \\
27 \cdot 4(1 \cdot 3) \\
26 \cdot 7(1 \cdot 3) \\
26 \cdot 4(1 \cdot 3) \\
27 \cdot 1(1 \cdot 3)\end{array}$ & $\begin{array}{l}30.4(1.4) \\
28.6(1.5) \\
27.7(1.5) \\
26.7(1.5) \\
25.3(1.3) \\
25.5(1.3) \\
26.9(1.7)\end{array}$ & $\begin{array}{l}\text { ns } \\
0 \cdot 05 \\
\text { ns } \\
\text { ns } \\
\text { ns } \\
\text { ns } \\
\text { ns }\end{array}$ \\
\hline
\end{tabular}

Mean IOP (SEM) in mmHg of 24 patients on prestudy and treatment day.

* $p$ Indicates significance values for differences between prestudy and treatment day determined by paired $t$ test. NS = not significant $(p>0.05)$. the protocol, 8 males and 16 females (age 36 to 82 years, mean 65 years). Nineteen patients had primary open-angle glaucoma, five had ocular hypertension. Prior to the washout period, nine had received $\beta$-adrenoceptor blocking agents alone, seven pilocarpine alone, three pilocarpine plus an adrenergic agonist, one guanethidine plus an adrenergic agonist, and one acetazolamide alone. Three patients had no prior ocular hypotensive therapy.

At 1000 on the prestudy diurnal curve day the IOP ranged from 24 to $45 \mathrm{mmHg}$, the mean being $30.5 \mathrm{mmHg}$ for the eyes to be treated with MK-927 and $30.6 \mathrm{mmHg}$ for the eyes to be treated with placebo (Table II). The mean differences between eyes did not exceed 0.8 $\mathrm{mmHg}$ at any time point. As expected, diurnal variation occurred, with the IOP being lower in the afternoon (Fig 2).

On the treatment day the eyes treated with MK-927 showed a sustained decrease of IOP throughout the diurnal curve, with a peak mean change from predose pressure of $-10.5 \mathrm{mmHg}$ (peak mean percentage change $-33 \cdot 1 \%$ ) at 4.5 hours after treatment (Table III). At eight hours after treatment the mean IOP of MK treated eyes had not returned to prestudy day levels. In contrast, placebo treated eyes showed a peak mean change of $-5 \cdot 1 \mathrm{mmHg}(-16 \cdot 6 \%)$ at $4 \cdot 5$ hours. At 8 hours the mean IOP had returned to prestudy day levels (Fig 2). When comparing prestudy and treatment-day diurnal curves we noted a significant difference in the mean IOP of the MK-927 treated eyes at all time points after treatment (Table II). In contrast, for the contralateral eyes we noted a significant difference between IOP on prestudy and treatment day only at 1 hour after treatment. The mean decrease in IOP in MK-927 treated eyes on the treatment day was significantly greater than the mean decrease on the prestudy day at each point after treatment, $\mathrm{p}<0.01$ (Table III).

To compensate for diurnal variation in the IOP we calculated the net change in IOP $(\Delta \Delta$ IOP) at each time point on the treatment day. For each time point this was defined as the change in IOP from immediately before treatment $(1000)$ on the treatment day minus the corresponding change in IOP from 1000 on the prestudy diurnal curve day. MK-927 treated eyes showed a peak mean $\Delta \Delta$-IOP of -7.5 $\mathrm{mmHg}$ at 4.5 hours after treatment, while the 


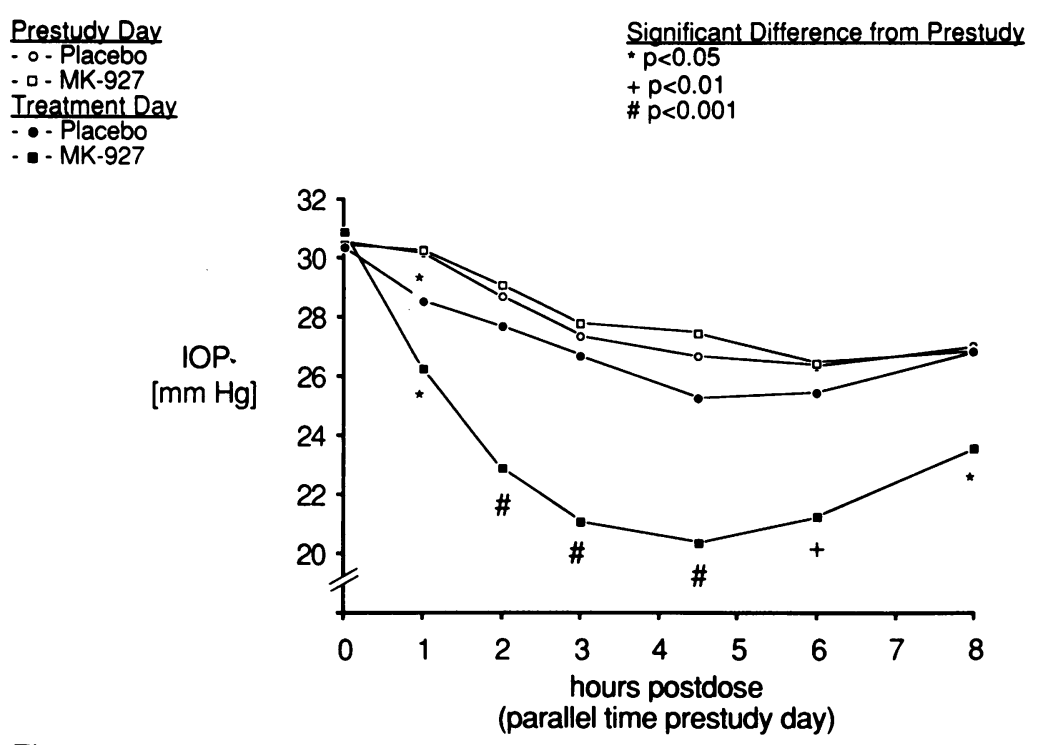

Figure 2: Mean IOP.

Diurnal curves on prestudy day $(\mathrm{O})$ and treatment day O). Level of significance between MK-927 and placebo treated eyes at the same time (paired t test); $n=$ 24 for each point

peak mean $\Delta \Delta$-IOP for placebo treated eyes was $-1.4 \mathrm{mmHg}$ and occurred at 1 hour after treatment (Fig 3). At each time point the mean $\Delta \Delta$-IOP was significantly greater for $\mathrm{MK}-927$
Figure 3: Mean net change in $I O P(\Delta \Delta-I O P)$ determined by: Fall of IOP from $t=0$ hour on treatment day minus fall of IOP from $t=0$ hour on pretreatment day with standard error of the mean. $\triangle \Delta-I O P$ for $M K-927$ treated eyes is significantly different from placebo treated eyes at all time points $(p<0.01)$.

- - Placebo

- - MK-927 treated eyes than for placebo treated eyes $(\mathrm{p}<0.01)$.

Pressure reduction was not analysed according to iris colour since the distribution was uneven (17 blue, three hazel, two green, two brown).

The patients were monitored for local side effects. Four patients reported bilateral blurring of vision and one patient bilateral foreign body sensation at 10 minutes after treatment. One patiënt had burning at $10 \mathrm{~min}$ in the MK-927 treated eye. Visual acuity remained unchanged in most patients and dropped one to three lines in five MK-927 treated eyes and in six placebo treated eyes, usually at 10 min after treatment. Mild bilateral corneal punctate erosions were seen towards the end of the day in 16 patients and were considered to be induced by repeated applanation tonometry. One patient had bilateral conjunctival hyperaemia. No systemic side effects were observed.

\section{Discussion}

MK-927 is a topical CAI which has been shown

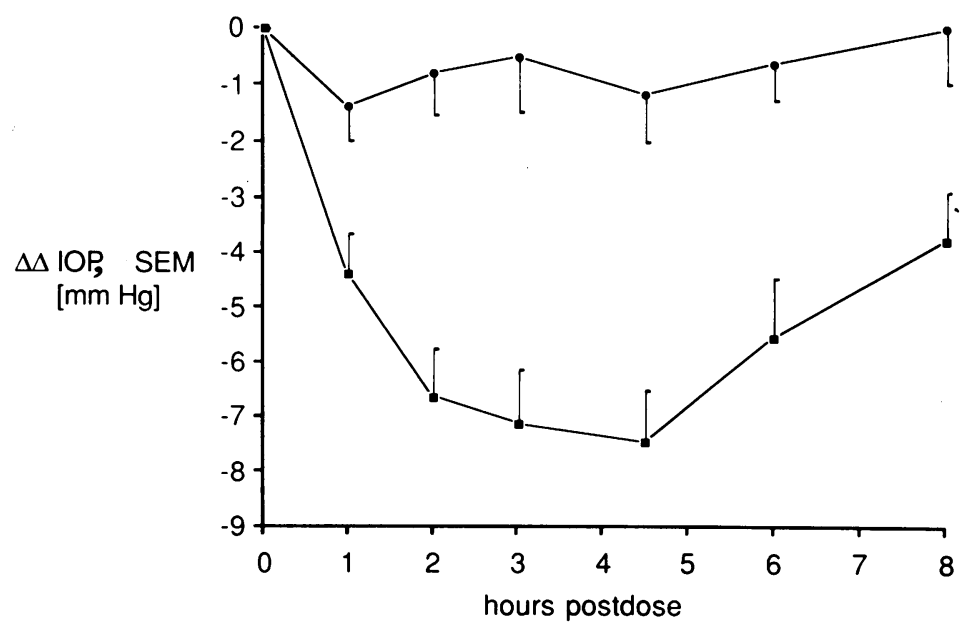

TABLE III Mean change and percentage change (with $S E M)$ from predose on treatment day

\begin{tabular}{|c|c|c|c|c|}
\hline \multicolumn{3}{|c|}{$M K-927$ treated eyes } & \multicolumn{2}{|c|}{ Placebo treated eyes } \\
\hline Time & Change $^{\star}$ & $\%$ Change & Change & \% Change \\
\hline $\begin{array}{l}1100 \\
1200 \\
1300 \\
1430 \\
1600 \\
1800\end{array}$ & $\begin{array}{l}-4 \cdot 6(0 \cdot 7) \\
-8 \cdot 0(0.9) \\
-9 \cdot 8(0.9) \\
-10 \cdot 5(0.9) \\
-9 \cdot 6(1.0) \\
-7 \cdot 3(0.6)\end{array}$ & $\begin{array}{l}-14 \cdot 7 \% \\
-25 \cdot 6 \% \\
-31 \cdot 4 \% \\
-33 \cdot 1 \% \\
-29 \cdot 9 \% \\
-23 \cdot 6 \%\end{array}$ & $\begin{array}{l}-1 \cdot 8(0.4) \\
-2.7(0.7) \\
-3.7(0.6) \\
-5 \cdot 1(0.5) \\
-4.8(0.4) \\
-3.5(0.8)\end{array}$ & $\begin{array}{l}-6 \cdot 0 \% \\
-9 \cdot 2 \% \\
-12 \cdot 4 \% \\
-16 \cdot 6 \% \\
-16 \cdot 0 \% \\
-12 \cdot 5 \%\end{array}$ \\
\hline
\end{tabular}

^IOP changes for MK-927 treated eyes are significantly different from those for placebo treated eyes at all time points $(p<0.01)$.

to have IOP lowering activity after single doses in several animal models and after three doses in man. In this study we show that in patients with primary open angle glaucoma or ocular hypertension a single drop of $2 \% \mathrm{MK}-927$ induced a sustained decrease in IOP over at least eight hours. A net peak mean reduction in IOP of $7.5 \mathrm{mmHg}$ above that due to diurnal variation alone occurred at 4.5 hours after treatment (Fig 3). This result is similar to that obtained in a multiple dose study in which three consecutive doses of 2\% MK-927 elicited a peak mean IOP decrease of $7 \cdot 7 \mathrm{mmHg}(26.9 \%) .^{14}$

A slight reduction of IOP in the contralateral placebo treated eyes might be deduced from Figure 2. However, this is significant at only one time point and is probably due to day-to-day changes in diurnal variation. Moreover, the amount of drug available for systemic absorption is so small that a contralateral effect based on a systemic effect is unlikely.

The patients did not complain of symptoms apart from transient blurring of vision and in one case of a transient burning sensation in an MK927 treated eye. This suggests good toleration of the drug. However, as the IOPs were measured immediately before application of the drug, in most cases the cornea was still anaesthetised when the drops were instilled, obviously limiting subjective symptoms.

The high level of activity which the drug shows after the application of a single drop is quite promising. It is expected that a topical CAI might avoid side effects common to systemic CAIs while retaining the advantage of substantial activity and little escape phenomena. If this proves to be true and the pressure reduction demonstrated here persists with chronic use of the drug, MK-927 might be suitable for the treatment of glaucoma or ocular hypertension. It is also likely that therapy with a topical CAI could be combined with that of other pressure lowering medications.

STATEMENT ON POSSIBLE PROPRIETARY OR COMMERCIAL INTEREST

Dr Lippa is a director, clinical research, and Dr Brunner-Ferber is an assistant director, clinical pharmacology; both are employed at Merck \& Co., Inc.

Drs Pfeiffer, Grehn, Hennekes, and Garus have no commercial or proprietary interest in the drug MK-927.

We acknowledge the contributions of Ms Coleen Clineschmidt, senior medical program co-ordinator, clinical research, Merck Sharp and Dohme Research Laboratories, for assistance in coordinating the various aspects of this study, and of Ms Karen Walton, Ms Deborah Panebianco, and Ms Ravanne Berman, statisticians, biostatistics, Merck Sharp and Dohme Research Laboratories, for performing the statistical analysis of the study data. 
1 Becker B. Decrease in IOP in man by a CAI, Diamox. Am $\mathcal{F}$ Ophthalmol 1954; 37: 13-5.

2 Foss RH. Local application of Diamox, an experimental study of its effect on the intraocular pressure. Am $\mathcal{f}$ Ophthalmol 1955; 39: 336-9.

3 Nagasubramanian S, Bloom J, Poinoosawmy D, et al. The effects of a topical acetazolamide preparation on IOP in patients with ocular hypertension. In: Krieglstein. GK ed. Glaucoma Update III. Heidelberg: Springer, 1987: 225-9.

4 Maren TH. Carbonic anhydrase: general perspectives and advances in glaucoma research. Drug Dev Res 1987; 10: 255advanc

5 Lewis RA, Schoenwald RD, Barfknecht CF, et al. Aminozolamide Gel: a trial of a topical CAI in ocular hypertension Arch Ophthalmol 1986; 104: 842-4.

6 Maren TH, Bar-Ilan A. Effect of 6-OH benzo[b]thiopene-2 sulfonamide, a new topical carbonic anhydrase (CA) inhibito on IOP in rabbits. Invest Ophthalmol Vis Sci 1987; 28 (suppl): 268.

7 Werner EB, Gerber DS, Yolande JY. Effect of a topical CAI, 6-OH benzo[b]thiopene-2-sulfonamide, on IOP in normotensive subjects. Canf Ophthalmol 1987; 22:316-9.

8 Ponticello GS, Freedman MB, Habecker C, et al. Thieno- thiopyran-2-sulfonamides: a novel class of water-soluble CAI. F Med Chem 1987; 30: 591-7.

9 Baldwin J, Ponticello G, Sugrue M, et al. MK-927, a water soluble, topically effective CAI. Read at the Third Chemical Congress of North America, Toronto, Canada, 5 June, 1988.

10 Maren TH, Bar-Ilan A. Ocular pharmacology and hypotensive activity of a topically active carbonic anhydrase (CA) inhibitor, a 4-alkylaminothienothiopyran-2-sulfonamide MK-927. Invest Ophthalmol Vis Sci 1988; 29 (suppl.): 16.

11 Sugrue MF, Gautheron P, Grove J, et al. MK-927: a topically effective ocular hypotensive carbonic anhydrase (CA) inhibitor in rabbits. Invest Ophthalmol Vis Sci 1988; 29 (suppl): 81 .

12 Wang RF, Serle JB, Podos SM, et al. The ocular hypotensive effect of the topical carbonic anhydrase (CA) inhibitor MK927 in glaucomatous monkeys. Invest Ophthalmol Vis $\mathrm{Sc}$ 1988; 29 (suppl): 16.

13 Lippa EA, von Denffer HA, Hofmann HM, et al. Loca tolerance and activity of MK-927, a novel CAI. Arch Ophthalmol 1988; 106: 1694-6.

14 Lippa E, Hofmann H, Feicht B, et al. MK-927: a topically effective CAI in patients. Read at the Third Congress of the European Glaucoma Society at Estoril, 1988. 